\title{
Micromorphological Features of Pan Horizon in the Soils Derived from Different Parent Materials
}

\author{
Yongseon Zhang, Yeon-Kyu Sonn*, Yong-Hee Moon, Kangho Jung, Hye-Rae Cho, and Kyeong-Hwa Han \\ Division of Soil and Fertilizer, National Academy of Agricultural Science, Korea \\ ${ }^{1}$ Korea National Park Service, National Geo-parks Secretary, Korea
}

(Received: July 14 2014, Revised: July 15 2014, Accepted: July 24 2014)

\begin{abstract}
We have five soil series of pan soils in South Korea out of 391 series: Gangreung, Bugog, Yeongog, Jangweon, and Pogog. Productivity decreases in pan soils as pan horizons impede percolation and capillary rise of water and intemupt root extension. This study was performed to investigate pedogenic processes of pan soils mainly located in footslope and river terrace by analyzing physicochemical properties and soil micro-morphology. Korean pan soils belong to Alfisols, Ultisols, or Inceptisols and have udic or aquic soil moisture regime, mesic temperature regime, and mixed mineral substances. Texture of pan horizons selected for the present study was mainly silty clay loam with clay contents ranging from 26.3 to $45.3 \%$ Bulk density of the pan horizons ranged from 1.4 to $2.1 \mathrm{Mg} \mathrm{m}^{-3}$ and their soil structure were subangular or angular structure. In terms of micromorphological structure, Bt horizon of Gangreung series was formed as platy and striated b-fabric structure possibly affected by uplift of coastal terrace following clay sedimentation by flood. Jangweon series showed micro-morphology of massive structure and crystallic $b$-fabric as macropores between coarse debris established by debris fall in slope were filled with silt-sized particles. The Bt horizons having massive structure and striated b-fabric in Yeongog, Pogog, and Bugog series implies that those horizons experienced horizontal mass flow after clay accumulation.
\end{abstract}

Key words: Pan, Bt, Micro-morphology, Structure

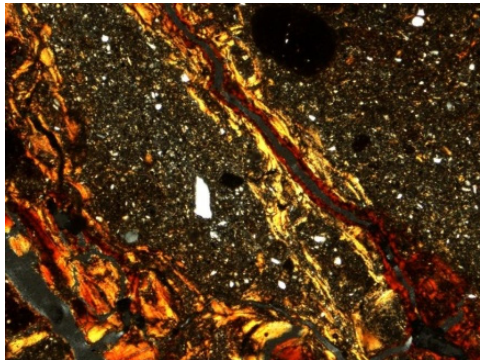

(a)

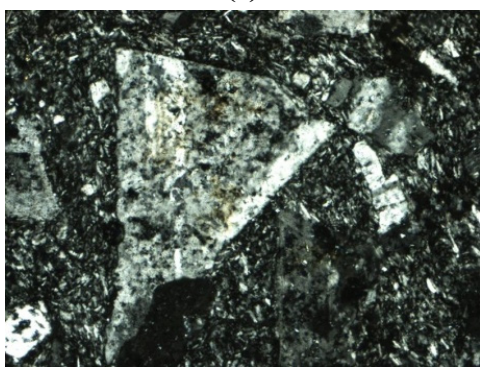

(d)

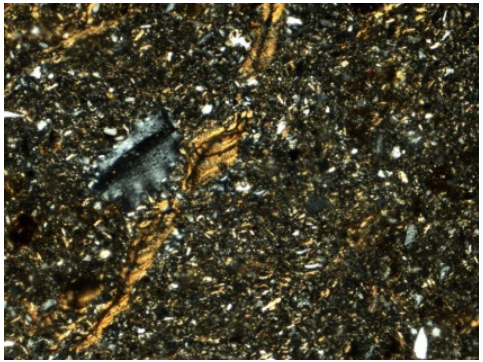

(b)

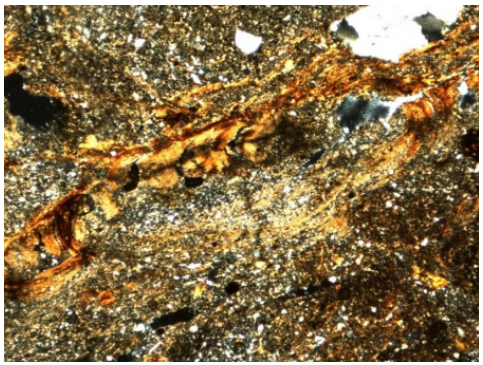

(e)

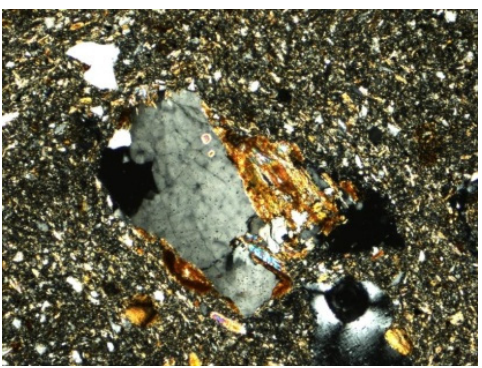

(c)

Micrographs of vertical thin section in pan horizons and argillic horizons. Frame width $5.2 \mathrm{~mm}$ : (a) Btx horizon of Gangreung series, (b) Bx horizon of Bugog series, (c) Btx horizon of Yeongog series, (d) Bx horizon of Jangweon series, (e) Btx horizon of Pogog series.

*Corresponding author : Phone: +82632382425, Fax: +82632383822, E-mail: sonnyk@korea.kr

${ }^{\S}$ Acknowledgement: This project was supported by National Academy of Agricultural Science (PJ007434). 


\section{Introduction}

토양의 반층 (盤層, pan)은 손으로 부서지지 않는 단단하 게 굳은 토층으로 용적밀도가 높고 유기물 함량이 낮은 광 물질의 단단한 층으로 알려져 있다 (Grossman and Carlisle, 1969; Steele et al. 1969). 반층은 식물 뿌리의 신장, 물의 침투, 모관 (毛管) 상승 등을 방해하기 때문에 작물 생산력 감소의 주요 (主要) 요인이 되고 있으며, Daniels and Fritton (1994)에 의하면 물 정체 대역 (帶域)이 경반층 위에서 형성 되어 임지에서 충분히 성장한 거목도 반층 토양에서는 태풍 에 도복 되는 현상이 나타난다 (Fig. 1).

미국 농무성 (Soil Survey Staff, 2010)에서는 새로운 토 양통 설정시 토양의 미세형태학적 특성에 관한 조사가 토양 분류의 주요한 기준이 되고 있다. 반층이 표토아래에서 형 성되는 깊이는 가변적이며, 경반층과 인접하는 상층에 점토 집적층이 있는 경우도 있고 없는 경우도 있으나 일반적으로 6 가지의 특징이 있다. 즉, 낮은 유기물 함량, 양토의 토성, 조립질의 각주상, 주상 및 아각괴상구조로, 단단하지만 수 중에서는 외력에 의해 거의 소성 변형을 동반하지 않고 파 괴되는 취성 (脆性, brittleness)을 보이며, 반층에 인접한 상부층보다 용적밀도가 높고 투수성이 낮은 특성이 있다.

토양 반층은 토양생성과정에서 토양입자가 서로 다져지 거나 경화된 층위로 이쇄반층 (易碎盤層, fragipan)과 난쇄 반층 (難碎般層, duripan)으로 나눌 수 있다. 이쇄반층은 흙 덩이를 물에 담가 두었을 때 다음 날 용적으로 $50 \%$ 이상이 풀어지고 건조시키면 물리적으로 단단해진다. 난쇄반층은 토양 수분 함량의 변화에 경도가 크게 변하지 않으며 경반 층의 흙 덩어리를 물이나 염산 $(\mathrm{HCl})$ 용액에서 오랫동안 침 적시켜도 $50 \%$ 이상 붕괴되거나 박리되지 않을 정도로 견고 하게 고결되어 있다 (Soil Taxonomy, 1999).

우리나라에서 391 개 토양 중 반층은 5 개 토양통 (강릉, 부곡, 연곡, 장원, 포곡통) 65 천ha (4.5\%)으로, 대지, 구릉지

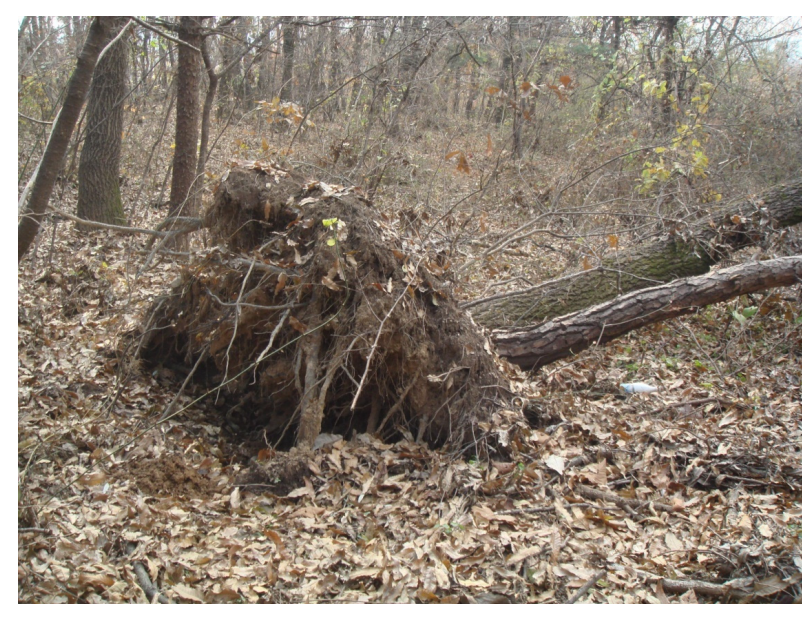

Fig. 1. A white oak fallen down by typhoon in the Bugog Series with pan soil.
및 산록경사지 하부에 주로 분포하고 있다 (NIAST, 2000b). 본 연구는 우리나라 반층토양 내에 생성된 경반층의 생성원 인을 구명하기 위하여 토양의 이화학적 특성과 편광현미경 하에서 토양의 미세형태학적 특성을 분석하였다.

\section{Materials and Methods}

반층 함유토양을 대상으로 강릉통은 강원 강릉시 강동면 정동진리 50-43 $\left(37^{\circ} 40^{\prime} 53^{\prime \prime} \mathrm{N}, 129^{\circ} 02^{\prime} 34^{\prime \prime} \mathrm{E}\right)$, 부곡통은 경기 남양주시 와부읍 도곡리 349-7 $\left(37^{\circ} 34^{\prime} 07^{\prime \prime} \mathrm{N}, 127^{\circ} 14^{\prime} 13^{\prime \prime} \mathrm{E}\right)$, 연곡통은 충남 서산시 부석면 송시리 $413-1\left(36^{\circ} 43^{\prime} 47^{\prime \prime} \mathrm{N}\right.$, $126^{\circ} 23^{\prime} 00^{\prime \prime} \mathrm{E}$ ), 장원통은 경북 청도군 청도읍 고수리 986 ( $35^{\circ}$ $\left.38^{\prime} 23^{\prime \prime} \mathrm{N}, 128^{\circ} 44^{\prime} 32^{\prime \prime} \mathrm{E}\right)$, 포곡통은 인천 계양구 다남동 산 $25-1\left(37^{\circ} 34^{\prime} 08^{\prime \prime} \mathrm{N}, 126^{\circ} 43^{\prime} 14^{\prime \prime} \mathrm{E}\right)$ 에서 토양 층위별로 채취하 였다.

토양의 이화학적 특성은 Soil Survey Laboratory Methods Manual (USDA, 2004)와 토양 및 식물체 분석법 (NIAST, 2000a)을 기준으로 분석하였다. 원추관입저항은 dynamic penetrometer (Eijkelkamp, 06.15 penetrologger)를 이용하 여 측정하였다. 토성분석은 $30 \% \mathrm{H}_{2} \mathrm{O}_{2}$ 로 유기물을 분해하 고, $5 \%$ sodium hexametaphosphate로 분산시켜 pipette법 으로 측정하였다. $\mathrm{pH}$ 는 토양과 물의 비율을 $1: 1$ 로 하여 초 자전극법으로 측정하였으며, 유기물 함량은 Walkley-Black 법으로 정량하였다. 치환성 $\mathrm{Ca}, \mathrm{Mg}, \mathrm{Na}$ 및 $\mathrm{K}$ 는 $1 \mathrm{~N}-\mathrm{NH}_{4} \mathrm{OAc}$ (pH 7.0) 용액으로 침출하여 원자흡광분광분석기로, 양이온 치환 용량 $(\mathrm{CEC})$ 는 $1 \mathrm{~N}-\mathrm{NH}_{4} \mathrm{OAc}(\mathrm{pH}$ 7.0)로 포화한 후 ethanol 로 과잉의 $\mathrm{NH}_{4}{ }^{+}$를 세척한 후 증류하여 정량하였다.

편광현미경으로 토양의 미세형태를 관찰하기 위하여 현 지 토양단면 조사 및 쟁기 바닥층에서 코어시료 채취 후 건 조기 내에서 $40^{\circ} \mathrm{C}$ 로 1 주일 정도 시료를 건조시키고 Polyester 수지를 토양입단에 가하여 토양공극을 포화시켰다. 수지로 포화된 시료를 실온에서 6 주, $40^{\circ} \mathrm{C}$ 건조기 내에서 1 주일 동 안 열처리하여 경화 시킨 후 절단하여 박편의 두께는 $30 \mu \mathrm{m}$ 이하가 되도록 연마 하였다. 토양 박편은 편광현미경을 이용 하여 개방니콜과 직교니콜 상태하에서의 토양 미세형태학적 특성을 Stoops와 Eswaran (1986)의 기술방법에 따라 분석 하였다.

\section{Results and Discussion}

반층은 증발량보다 강우량이 많고 미사가 풍부한 빙력토, 호상 퇴적물, 붕적토, 황토, 홍적대지 (단구지)에서 형성 되 지만 홍함지와 잔적토에서는 발견되지 않으며, 지형적으로 배수가 느리거나 중간의 지형적 위치나, 생성론적으로 습윤 과 건조가 수반되는 곳에서 주로 형성되고 있다 (Bockheim and Hartemink, 2013). 반층 함유 토양단면의 형태적 특징 
Table 1. General characteristics of soil profiles with pan horizons.

\begin{tabular}{cccc}
\hline \hline Soil series & Soil classification (USDA) & Topography & Drainage class \\
\hline Gangreung & Fine, mixed, mesic family of Aquic Fragiudalfs & Coastal Terraces & Moderately well drain \\
Bugog & Fine loamy, mixed, mesic family of Typic Fragiudults & Mountain foot slope & Moderately well drain \\
Yeongog & Fine silty, mixed, mesic family of Aquic Fragiudults & Mountain foot slope & Moderately well drain \\
Jangweon & Fine loamy, mixed, mesic family of Typic Fragiudepts & Valley and fans & Moderately well drain \\
Pogog & Fine, mixed, mesic family of Aquic Fragiudalfs & Mountain foot slope & Moderately well drain \\
\hline
\end{tabular}

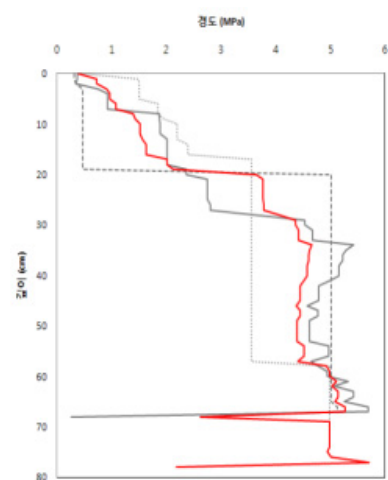

(a)

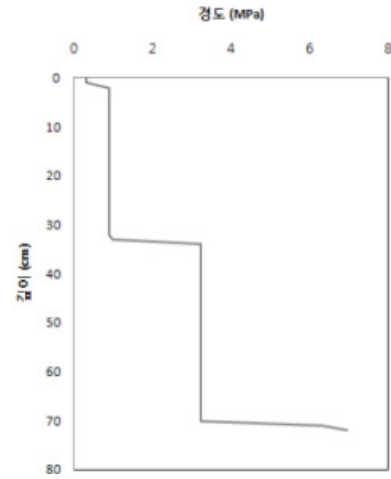

(d)

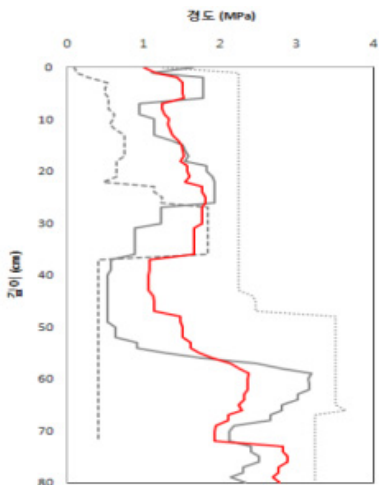

(b)

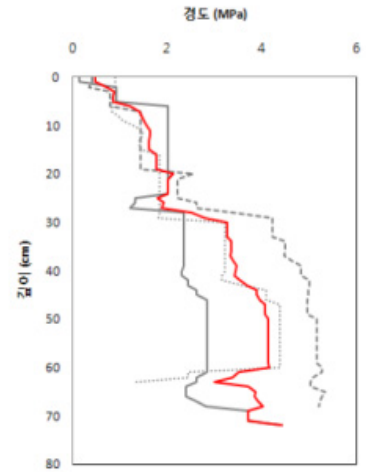

(e)

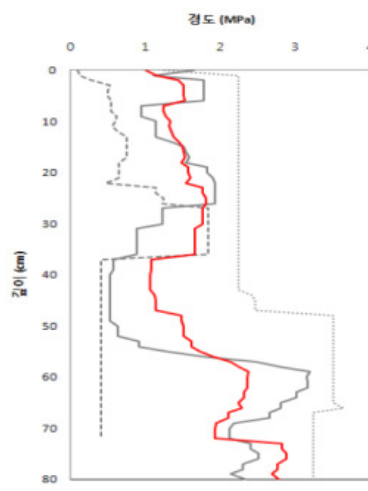

(c)

Fig. 2. Changes in soil strength with depth for (a) Gangreung, (b) Bugog, (c) Yeongog, (d) Jangweon, and (e) Pogog series.

과 모재 및 분포지형은 Table 1과 같다.

우리나라 반층 토양은 토양목상 Alfisols, Ultisols, Inceptisols 로 분류되며, 토양수분은 습윤 (udic)권역이나 과습윤 (aquic) 권역, 토양온도는 온대상 (mesic)권역, 광물조성상 혼합광 물등급에 속하였다. 세계적으로 분포하는 반층의 토양분류상 분포와 비교하면, 12 개 토양목상 4 개의 토양목인 Alfisols, Ultisols, Inceptisols, Spodosols에 존재하며, 토양수분은 과 습윤 (aquic)권역이 많았고, 토양온도와 광물조성은 모든 토양이 온대상 (mesic)권역의 혼합광물 등급에서 발견되고 있어 유사한 특징을 보이는 것으로 고찰되었다 (Harlan et al., 1977; Janes et al.,1995).

Soil Taxonomy (USDA, 1999)에서 반층은 최소 $15 \mathrm{~cm}$ 이 상으로 조립질 구조를 갖는 토층으로, Fig. 2에서 토양별로 원추저항 $2.0 \mathrm{Mpa}$ 이상의 토심이 출현하기 시작하는 토층 의 깊이는 강릉통, 부곡통, 포곡통은 토심 $25 \mathrm{~cm}$ 이하에서, 연곡통은 토심 $60 \mathrm{~cm}$ 이하이었으며, 장원통은 표토의 자갈
함량이 $30 \%$ 이상으로 심토 원추저항 깊이를 측정할 수 없었 다. Bryant (1989)와 Bullock et al. (1974)에 따르면, 반층 두께는 수축과 팽창으로 증가되는데 공극이 형성된 후 건조 기에 인접한 상부층 물질이 공극을 통하여 이동하는 것으로 알려져 있으며, 습윤과 건조는 암석학적으로 불연속성과 입 자의 밀집충진으로 탄산함량이 낮아지고, 공극율의 감소를 유발한다. 점토, 탄산염, 석고, 철, 규소 등의 토양생성학적 축척이나 이들의 결합은 딱딱하고 조밀한 층위의 형성을 유 발한다.

토양의 물리-화학적 특성을 Table 2에서 살펴보면, 반층 토양은 약한 판상에서 아각괴상구조, 높은 용적밀도 1.5 $1.9 \mathrm{Mg} \mathrm{m}^{-3}$ 를 가진다 (Grossman 등, 1959). 반층이 존재하 는 $\mathrm{Bx}$ 또는 $\mathrm{Btx}$ 의 토양구조는 아각괴상과 각괴상 구조가 대 부분으로 판상구조를 발견할 수 없었다. 반층 대상토양에서 반층의 용적밀도는 $1.4 \sim 2.1 \mathrm{Mg} \mathrm{m}^{-3}$ 의 범위로, Ciolkosz et al. (1995)의하면 반층 토양은 일반적으로 토심 $60 \mathrm{~cm}$ 이내 
Table 2. Soil physical properties of soil profiles with pan horizons.

\begin{tabular}{|c|c|c|c|c|c|c|c|c|}
\hline \multirow{2}{*}{ Soil series } & \multirow{2}{*}{$\begin{array}{c}\text { Soil } \\
\text { Horizons }\end{array}$} & \multirow{2}{*}{$\begin{array}{l}\text { depth } \\
(\mathrm{cm})\end{array}$} & \multirow{2}{*}{ Soil Structure } & \multirow{2}{*}{$\begin{array}{l}\text { Buljk density } \\
\left(\mathrm{Mg} \mathrm{m}^{-3}\right)\end{array}$} & \multicolumn{3}{|c|}{ Particle size distribution (wt, \%) } & \multirow{2}{*}{$\begin{array}{l}\text { Texture } \\
\text { (USDA) }\end{array}$} \\
\hline & & & & & Sand & Silt & Clay & \\
\hline \multirow{4}{*}{ Gangreung } & A & $0-22$ & Granular & 1.42 & 20.9 & 43.1 & 36.0 & $\mathrm{SiC}$ \\
\hline & BAt & $22-52$ & Subangular blocky & 1.51 & 18.8 & 44.2 & 37.0 & $\mathrm{SiC}$ \\
\hline & Btx1 & $52-100$ & Angular blocky & 1.42 & 16.6 & 43.9 & 39.5 & $\mathrm{SiC}$ \\
\hline & Btx2 & $100-172$ & Angular blocky & 1.43 & 16.2 & 42.8 & 41.0 & $\mathrm{SiC}$ \\
\hline \multirow{4}{*}{ Bugog } & Ap & $0-20$ & Granular & 1.23 & 27.1 & 48.3 & 24.6 & $\mathrm{SiL}$ \\
\hline & BAt & $20-35$ & Subangular blocky & 1.43 & 20.6 & 47.6 & 31.8 & $\mathrm{SiCL}$ \\
\hline & $\mathrm{Bt}$ & $35-45$ & Subangular blocky & 1.54 & 12.4 & 58.9 & 28.7 & $\mathrm{SiCL}$ \\
\hline & Btx & $45-60$ & Subangular blocky & 1.64 & 15.8 & 57.9 & 26.3 & $\mathrm{SiCL}$ \\
\hline \multirow{4}{*}{ Yeongog } & A & $0-20$ & Granular & 1.05 & 46.0 & 40.6 & 13.4 & $\mathrm{~L}$ \\
\hline & BA & $20-38$ & Granular & 1.27 & 10.9 & 65.9 & 23.2 & $\mathrm{SiCL}$ \\
\hline & Btx1 & $38-62$ & Angular blocky & 1.63 & 12.7 & 56.0 & 31.3 & $\mathrm{SiCL}$ \\
\hline & Btx2 & $62-90$ & Angular blocky & 1.54 & 11.7 & 59.3 & 29.0 & $\mathrm{SiCL}$ \\
\hline \multirow{3}{*}{ Jangweon } & A & $0-15$ & Subangular blocky & 1.22 & 21.5 & 58.3 & 20.2 & $\mathrm{SiL}$ \\
\hline & $\mathrm{BA}$ & $15-50$ & Subangular blocky & 1.28 & 21.9 & 58.8 & 19.3 & $\mathrm{SiL}$ \\
\hline & $\mathrm{Bx} 1$ & $50-65$ & Angular blocky & 2.13 & 17.9 & 61.5 & 20.6 & $\mathrm{SiL}$ \\
\hline \multirow{4}{*}{ Pogog } & Ap & $0-20$ & Subangular blocky & 1.41 & 39.9 & 44.4 & 15.7 & $\mathrm{~L}$ \\
\hline & BAt & $20-40$ & Subangular blocky & 1.53 & 9.5 & 55.3 & 35.2 & $\mathrm{LiC}$ \\
\hline & Btx & $40-55$ & Angular blocky & 1.72 & 9.8 & 58.1 & 32.1 & $\mathrm{SiCL}$ \\
\hline & BCtx & $55-85$ & Angular blocky & 1.75 & 9.2 & 55.1 & 35.7 & SiCL \\
\hline
\end{tabular}

Table 3. Soil chemical properties of soil profiles with pan horizons.

\begin{tabular}{|c|c|c|c|c|c|c|c|c|c|c|}
\hline \multirow{2}{*}{ Soil series } & \multirow{2}{*}{ Horizon } & \multirow{2}{*}{$\begin{array}{c}\mathrm{pH} \\
(1: 5)\end{array}$} & \multirow{2}{*}{$\begin{array}{c}\mathrm{EC} \\
\left(\mathrm{dS} \mathrm{m} \mathrm{m}^{-1}\right)\end{array}$} & \multirow{2}{*}{$\begin{array}{c}\mathrm{OM} \\
\left(\mathrm{g} \mathrm{kg}^{-1}\right)\end{array}$} & \multirow{2}{*}{$\begin{array}{l}\text { Ave } \mathrm{P}_{2} \mathrm{O}_{5} \\
\left(\mathrm{mg} \mathrm{kg}{ }^{-1}\right)\end{array}$} & \multicolumn{4}{|c|}{ Ext. cation $\left(\mathrm{cmol}_{\mathrm{c}} \mathrm{kg}^{-1}\right)$} & \multirow{2}{*}{$\begin{array}{c}\text { CEC } \\
\left(\mathrm{cmol}_{\mathrm{c}} \mathrm{kg}^{-1}\right)\end{array}$} \\
\hline & & & & & & $\mathrm{Ca}$ & $\mathrm{K}$ & $\mathrm{Mg}$ & $\mathrm{Na}$ & \\
\hline \multirow{4}{*}{ Gangreung } & A & 6.3 & 0.78 & 21 & 6 & 7.02 & 0.46 & 1.12 & 0.07 & 14.1 \\
\hline & BAt & 6.5 & 0.55 & 17 & 3 & 7.72 & 0.31 & 1.57 & 0.07 & 15.4 \\
\hline & Btx1 & 7.1 & 0.26 & 13 & 3 & 8.07 & 0.14 & 1.23 & 0.09 & 15.6 \\
\hline & Btx2 & 7.1 & 0.24 & 14 & 3 & 7.82 & 0.11 & 1.43 & 0.11 & 17.7 \\
\hline \multirow{4}{*}{ Bugog } & Ap & 6.9 & 0.41 & 18 & 82 & 5.54 & 0.95 & 2.34 & 0.11 & 14.9 \\
\hline & BAt & 6.0 & 0.24 & 9 & 1 & 1.63 & 0.43 & 1.03 & 0.07 & 12.1 \\
\hline & $\mathrm{Bt}$ & 4.8 & 0.21 & 7 & 3 & 1.72 & 0.35 & 1.30 & 0.07 & 13.2 \\
\hline & Btx & 4.9 & 0.19 & 6 & 4 & 2.28 & 0.76 & 1.83 & 0.50 & 9.6 \\
\hline \multirow{4}{*}{ Yeongog } & A & 7.6 & 0.35 & 19 & 254 & 5.43 & 0.51 & 2.58 & 0.20 & 23.2 \\
\hline & BA & 7.0 & 0.32 & 22 & 23 & 5.27 & 0.46 & 2.39 & 0.18 & 24.0 \\
\hline & Btx1 & 6.7 & 0.31 & 10 & 3 & 4.68 & 0.37 & 0.57 & 0.09 & 19.8 \\
\hline & Btx2 & 6.2 & 0.29 & 7 & 3 & 4.46 & 0.22 & 0.49 & 0.10 & 26.4 \\
\hline \multirow{3}{*}{ Jangweon } & A & 4.9 & 0.15 & 23 & 279 & 0.99 & 0.18 & 0.28 & 0.03 & 16.2 \\
\hline & BA & 4.9 & 0.19 & 17 & 170 & 0.87 & 0.10 & 0.28 & 0.03 & 13.5 \\
\hline & Bx1 & 4.8 & 0.19 & 8 & 5 & 1.17 & 0.14 & 0.38 & 0.03 & 11.4 \\
\hline \multirow{4}{*}{ Pogog } & Ap & 6.5 & 0.43 & 19 & 274 & 6.22 & 1.28 & 2.74 & 0.12 & 8.9 \\
\hline & BAt & 5.3 & 0.43 & 6 & 3 & 1.55 & 1.50 & 1.28 & 0.05 & 14.9 \\
\hline & Btx & 5.9 & 0.35 & 6 & 1 & 2.47 & 1.04 & 1.10 & 0.06 & 13.9 \\
\hline & $\mathrm{Cx}$ & 4.9 & 0.37 & 6 & 2 & 2.08 & 0.51 & 0.65 & 0.05 & 15.4 \\
\hline
\end{tabular}

에 근계점 이상의 용적밀도 $1.6 \mathrm{Mg} \mathrm{m}^{-3}$ 이상 존재하는 것으 로 규정하고 있으나 토양모재에 따라 차이를 보여 붕적토, 빙퇴토 〉> 홍적층 (단구지) > 황토 순으로 용적밀도가 진단 기준이 될 수 없는 것으로 고찰되었다.

반층의 토성은 미사질식양토가 대부분으로 점토함량은
26.3 45.3\%이었다. 토양모재의 토성이 반층 형성에 영향 을 미쳐 양토와 미사질 양토인 토성에서 주로 형성되는데, 특히 취성이 양토에서 잘 나타난다 (Zimmerman and Kardos, 1961). 모래와 점토가 너무 많은 경우 반층은 형성되지 않으 며, 점토함량이 많은 경우 토양시료는 압착되지만 소성이 형 
성되어 취성이 나타나지 않는 것으로 알려져 있다 (Thompson et al, 1987). 표토층과 비교할 때 점토집적층의 점토함량 증가량은 $1.1 \sim 2.4$ 배로 평균 1.6 배 이상이었으며, 점토증가 량이 1.2 배 이하인 토양은 강릉, 부곡, 장원통이었다. 표토 에서 $\mathrm{Bt}$ 층인 심토로 내려갈수록 증가되나 다시 심토에서 기 층으로 내려가면 감소하는 경향을 보이는데, 이는 표토의 점토가 물리적인 작용으로 $\mathrm{B}$ 층에 집적된 $\mathrm{Bt}$ 층 토양의 전형 적인 특징을 보이고 있다 (Walker and Hutka, 1979). 또한, 토양 중 물질이동에 따른 집적현상은 점토의 경우 표토보다 심토의 점토함량이 $10 \%$ 이상 증가함에 따라 철분도 $1 \%$ 이 상 동반하여 증가한다 (Dijkerman et al., 1967; Gile, 1979; Miles and Franzmeier, 1981). 점토 집적층은 강우에 의해 서 $\mathrm{A}$ 층의 염류가 용탈되어 심토에 집적된 결과로 치환성 염 류의 함유량도 표토보다 심토에서 높은 것으로 알려져 있다 (Chesworth, 1973; Childs et al., 1983).

토양의 화학적 특성을 Table 3에서 살펴보면, 반층 대상 토양에서 반층의 $\mathrm{pH}$ 는 $4.8 \sim 6.7$ 로 전반적으로 산성을 띠고 있었다. 반층 함유토양은 습윤지역에서 반층토양은 낮은 $\mathrm{pH}$ 하에서 형성되고 이쇄반층의 $\mathrm{pH}$ 는 인접하는 상층이나 하층보다 낮은 $\mathrm{pH}$ 를 보이는데 (Miller et al., 1993), 임지인 강릉통은 표토에서 반층으로 내려 갈수록 대체로 높아진 반 면에 부곡통, 연곡통, 장원통, 포곡통의 농경지 토양에서는 경작에 따른 석회 등 비료사용으로 이러한 경향이 나타나지 않았다. 또한 반층 함유 층위의 양이온치환용량 $(\mathrm{CEC})$ 과 유 기물 함량을 인접하는 토층과 비교하면, 강릉통을 제외하고
인접하는 상위층보다 낮았다. 이는 점토와 더불어 무정형 aluminosilicate (알루미노규산염)이 토괴로 유입되면, 광물 입자간 결합으로 용적밀도가 증가하고 토양 표면적이 감소 하는 것으로 고찰되었다 (Bridges and Bull,1983; Franzmeier et al.,1989; Karathanasis 1989).

광물은 보통 불투명한 것처럼 보이지만 금속 광물을 제 외한 비금속 광물들은 대개 $0.03 \mathrm{~mm}$ 이하의 두께에서는 빛 을 통과시키기 때문에 편광 현미경에서 여러 가지 성질을 관찰할 수 있다 (Buol and Hole, 1959).

반층토양의 미세형태학적 특성을 살펴보기 위해 불교란 시료를 채취하여 박편을 제작한 후 편광현미경의 개방니콜 상태에서 관찰된 미세형태학적 구조를 Fig. 3에 도시하였다.

전체적으로 경반층 $(\mathrm{Bx})$ 의 주요한 점토집적 현상은 토양 공극 표면의 점토피막이었으며, 장원통은 공극사이에 점토 와 미사가 충진되는 형태가 관찰되었다. 조립질대 미립질 입자의 분포 (c/f)를 살펴보면, 장원통은 단립상 (單粒狀, monic related distribution), 기타 4 개의 토양통은 밀집반 상 (密集斑狀, close porphyric related distribution)이었다. 토양박편 특성에서 밀집된 입자구조 (Closely-Packed)는 점 토에 의한 입자간 가교현상과 점토공극 피막 특성을 보인다 (Stoops, 2003).

미세형태학적 토양구조를 살펴보면, 강릉통은 압력을 받 은 모암의 기질이 세립 또는 미립질로 토양기질의 건조와 습윤의 반복하에서 수축과 팽창작용에 의해 형성된 판상 (板狀)이 주요한 구조이었는데, 판상 (板狀)의 미세구조는

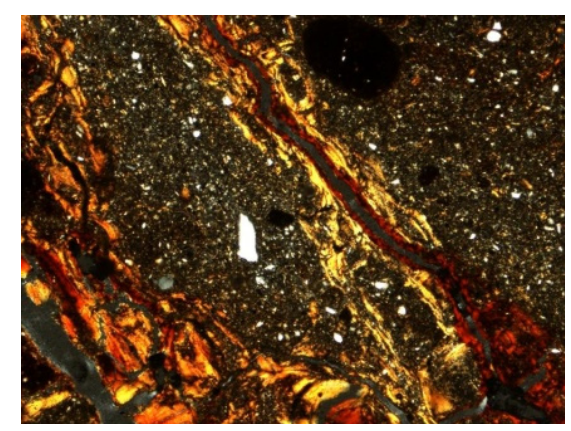

(a)

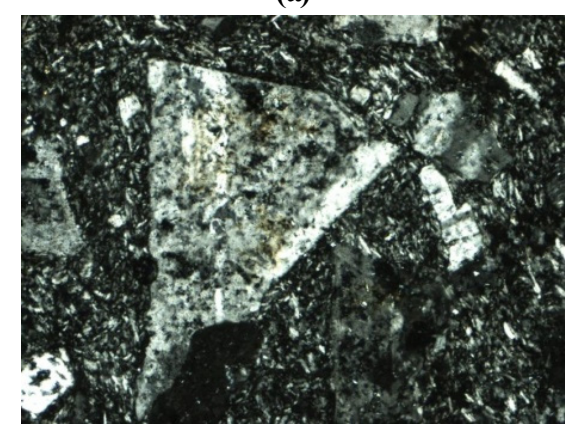

(d)

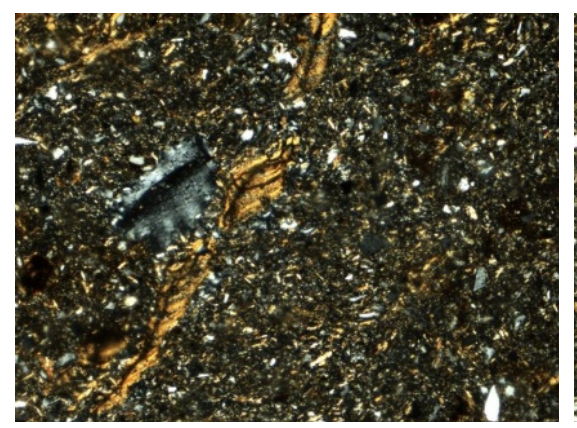

(b)

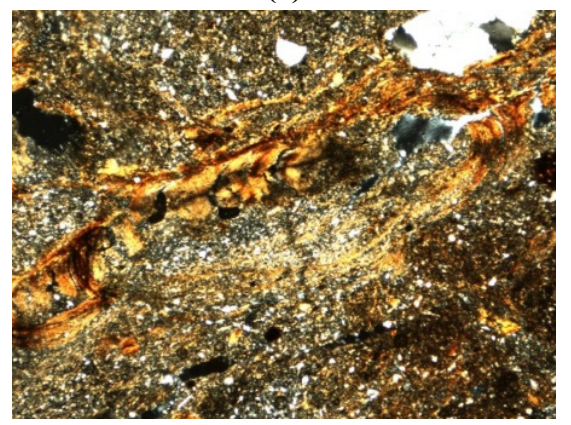

(e)

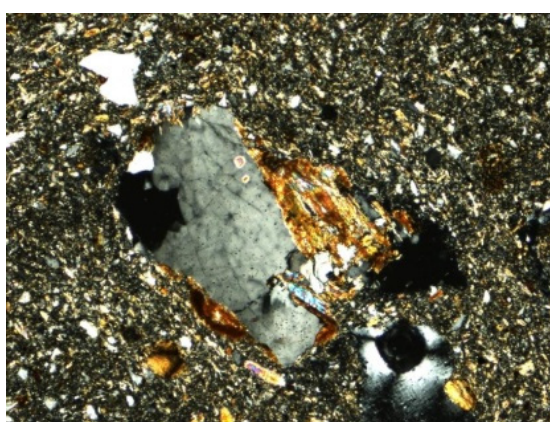

(c)

Fig. 3. Micrographs of vertical thin section in pan horizons and argillic horizons with clay and silt coatings in crossed polarized light. Frame width $5.2 \mathrm{~mm}$ : (a) Btx horizon of Gangreung series, (b) Bx horizon of Bugog series, (c) Btx horizon of Yeongog series, (d) Bx horizon of Jangweon series, (e) Btx horizon of Pogog series. 
Table 4. Main microstructure, b-fabric, and groundmass related to voids, grains and aggregates in Bt or Bx horizons of pan soils

\begin{tabular}{cccccc}
\hline \hline $\begin{array}{c}\text { Soil series } \\
\text { name }\end{array}$ & Microstructure & b-fabric & Groundmass & \multicolumn{2}{c}{ Clay \& Silt Coatings } \\
\cline { 3 - 6 } & & & Void & Grain & Aggregate \\
\hline Gangreung & Platy & Stipple-speckled & Yellow-reddish brown Clay and some silt & $\bigcirc$ & \\
Bugog & Massive & Mosaic-speckled & Yellowish brown Clay and some silt & $\bigcirc$ & \\
\hline Yeongog & Massive & Mosaic-speckled & Yellowish brown Clay and some silt & $\bigcirc$ & \\
\hline Jangweon & Massive & Crystallitic & Grayish brown Clay and Silt & $\bigcirc$ & $\bigcirc$ \\
\hline Pogog & Massive & Mosaic-speckled & Yellowish brown Clay and some silt & $\bigcirc$ & \\
\hline
\end{tabular}

점토의 퇴적작용과 건조보다 습윤상태가 지속되는 토양에 서 발달하는 것으로 알려져 있다 (Berg, 1984). 부곡통, 연 곡통, 장원통, 포곡통은 모양의 기질이 조립자인 토양은 구 성광물간 풍화도 차이에 의해 이분해성 풍화물이 용탈되어 무상 구조 (massive structure)를 보였다.

토양입자의 구성양상은 편광현미경 하에서 복굴절 현상이 나타나므로 b-fabric (birefringence)라고도 하는데, b-fabric 은 압력작용과 건조 및 습윤에 의해 수축작용이 우세한 토 양 (Bronger and Catt, 1989.)에서는 호상 (縞狀, striated $\mathrm{b}$-fabric)을 이루게 되는 토양으로 강릉통, 부곡통, 연곡통, 포곡통이었다. 한편, 각력의 석영과 장석 사이에 미사와 점 토가 충진된 장원통은 결정상 (結晶相, crystallic b-fabric) 이 주요한 b-fabric으로 판단되었다.

점토집적층 토양기질의 주요한 색상은 황적색, 적갈색, 회갈색으로 해안단구지에 분포하는 토양인 강릉통은 황색 $\sim$ 적색이었으며, 점토 집적층의 특징은 $\mathrm{A}$ 층보다 뚜렷한 점 토의 증가로 밝은색을 띠고 있었다. 산록경사지에 분포하는 토양인 부곡통, 연곡통, 포곡통은 황색 적색이었으며, 곡 간선상지 분포하는 토양인 장원통은 회색이었는데, 이는 Bt 층이 장기간 물에 잠기게 되었기 때문으로 판단된다 (Ponti, 1985).

미세형태학적 토양구조와 토양입자의 복굴절 현상 (birefringence)을 중심으로 반층토의 특성을 살펴보면, 해 안단구지에 분포하는 강릉통은 점토집적 $(\mathrm{Bt})$ 후 융기시 압 력으로 판상 (板狀)구조와 호상 (縞狀, striated b-fabric), 곡간 및 선상지에 분포하는 장원통은 경사지에서 암설 낙하 후 주로 미사가 모래 및 자갈 사이 공극에 충진되어 무상구조 (massive structure)와 결정상 (結晶相, crystallic b-fabric) 이 관찰되었다. 산록경사지에 분포하는 연곡통, 포곡통, 부 곡통에서는 기존 점토집적 (Bt) 후 일정한 방향성 없이 중력 이동에 의한 압력의 영향으로 무상구조 (massive structure) 와 호상 (縞狀, striated b-fabric)이 관찰되었다.

\section{References}

Berg, R. C. 1984. The origin and earllly genesis of clay bands in youthful sandy soils along Lake Michigsn. U.S.A. Geoderma.
32:45-62.

Bockheim, J. G. and A. E. Hartemink. 2013. Soils with fragipans in the USA. Catena 104:233-242.

Bridges, E. M, and P. A. Bull. 1983. The role of silica in the formation of compact and indurated horizons in the soils of the South Wales. p.605-613. In P. Bullock and C.P. Murphy(ed.) Soil micromorphology. Vol. 2. Soil genesis. AB Acad. Publ., Berkhamsted, England.

Bryant, R. B. 1989. Physical processes of fragipan formation. p. 141-150. in N.E. Smeck and E.J. Ciolkosz(ed.) Fragipans: Their occurrence, classification, and genesis. SSSA. Spec. Publ. 24. SSSA. Madison, WI.

Bullock, P., M. H. Milford, and M. G. Cline. 1974. Degradation of argillic horizons in Udalf soils in New Yok state. Soil Sci. Soc. Am. Proc. 38:621-628.

Buol, S. W. and F. D. Hole. 1959. Some characteristics of clay skins on peds in the B horizon of a Gray-Brown Podzolic soil .Soil Sci. Soc. Am. Proc. 23:239-241.

Chesworth. W. 1973. The parent material effect and the genesis of soils. Geoderma 10:215-225.

Childs, C. W., R. L. Parfitt, and H. Lee. 1983. Movement of aluminumas an inorganic complex in some podzolized soils, New Zealand. Geoderma 29:139-155.

Ciolkosz, E. J., W. J. Waltman, and N. C. Thurman. 1995. Fragipans in Pennsylvania soils. Soil Survey Horizons 36: 5-20.

Daniels, M. B. and D. D. Fritton. 1994. Groungwater mounding below a surface line square in a Typic Fragiudalf. Soil Sci. Soc. Am. J. 58:77-85.

Dijkerman, J. C., M. G. Cline, and G. W. Olson. 1967. Properties and genesis of texrural subsoil lamellae. Soil Sci. 104:7-16.

Franzmeier, D. P., L. D. Norton, and G. C. Stenhardt. 1989. Fragipan formation in loses of the Midwestern United States P. 66-97 In N.E. Smeck and E. J. Ciolkosz (ed.) Fragpans: Their occurrence. classification and genesis. SSSA, Spec. Publ. 24. SSSA, Madison, WI.

Gile, L. H. 1979. Holocene soils in eolian sediments of Bailey, County Texas. Soil Sci. Soc. Am. Proc. 43:994-1003.

Grossman, R. B. and F. J. Carlisle. 1969. Fragipan soils of the Eastern United States. Adv. Agron. 21:237-239.

Grossman, R. B., I. Stephen, J. B. Fehrenbacher, A. H. Beavers, and J. M. Parker, 1959. Fragipan soils of Illinois: II, 
Mineralogy in reference to parent material uniformity of Hosmer silt loam. Soil Science Society of America Proceedings 23, 7-73.

Harlan, P. W., D. P. Franzmeier, and C. B. Roth. 1977. Soil formation on loess in southwestern Indiana: II. Distribution of clay and free oxides and fragipan formation. Soil Sci. Soc. Am. J. 41:99-103.

Janes, H. R., M. D. Ransom, and R. J. Miles. 1995. Fragipan genesis in polygenetic soils on the Springfield Planteau of Missouri. Soil Sci. Soc. Am. J. 59:151-160.

Karathanasis, A. D. 1989. Solution chemistry of fragipans thermodynamic approach to understanding fragipan formation. p. 113-139. In N.e. Smeck and E. J. Ciolkosz(ed.) Fragipan; Their occurrence, classification, and genesis. SSSA, Spec. Publ. 24. SSSA, Madison, WI.

Miles, R. J. and D. P. Franzmeier. 1981. A lithosequence of soils firmed in dune sand. Soil Sci. Soc. Am. J. 45:362-367.

Miller, M. B., T. H. Cooper, and R. H. Rust. 1993. Differentiation of eluvial fragipan from dense glacial till in northern Minnesota. Soil Sci. Soc. Am. J. 57:787-796.

NIAST. 2000a. Methods of soil chemical analysis. National Institute of Agricultural Science and Technology, RDA, Suwon, Korea.

NIAST. 2000b. Taxonomical Classification of Korean Soils. National Institute of Agricultural Science and Technology, RDA, Suwon, Korea.

Ponti, D. J. 1985. The Quateermary alluvial sequence of the Antelope Valley, Califomia. Geol. Soc. Am. Spec. Pap. 203:
79-96

Soil Survey Staff, 2010. Keys to Soil Taxonomy, 11th edition. USDA, National Resources Conservation Service, National Soil Survey Center, Lincoln, NE.

Steele, F., R. B. Daniels, E. E. Gamble, and L. A. Nelson. 1969. Fragipan horizons and Be masses in the middle Coastal Plain of north Carolina. Soil Sci. Soc. Am. Proc. 33:752-755.

Stoops, G. and H. Eswaran. 1986. Soil micromorphology. Van Nostrand Rheinhold soil science series. Van Nostrand Reinhold. $345 p$.

Stoops, G., 2003. Guidelines for Analysis and Description of Soil and Regolith Thin Sections. Soil Science Society of America, Madison, WI, 184p.

Thompson, P. J., I. J. Jansen, and C. L. Hooks. 1987. Penetrometer resistance and bulk density parameters for predicting root system performance in mine soils. Soil Sci. Soc. Am. Proc. J. 51:1288-1293.

USDA-NRCS, 2004. Soil Survey Laboratory Methods Manual. Soil Survey Investigations Report No. 42. Version 4.0. USDA-NRCS. Lincoln, NE. 700p.

USDA, Soil Survey Staff. 1999. Soil Taxonomy. A basic system of soil classification for making and interpreting soil surveys. 2nd ed. Agric. Handbook 436. US.

Walker, P. H. and J. Hutka. 1979. Size characteristics of soils and sediments with special reference to clay fractions. Aust. J. Soil Res. 17:383-104.

Zimmerman, R. P. and L. T. Kardos. 1961. Effect of bulk destiny on root growth. Soil Sci. 91:280-288. 